\title{
A Case of Lymphomatoid Granulomatosis-Like Lung Lesions with Abundant Infiltrating IgG4-Positive Plasma Cells Whose Serum IgG4 Levels Became High Following the Start of Corticosteroid Therapy
}

\author{
Tomoko Miyashita ${ }^{1}$, Katsunobu Yoshioka ${ }^{1}$, Tomoyuki Nakamura ${ }^{1}$, Yuki Kubo ${ }^{2}$, \\ Takeshi Inoue $^{2}$, Takashi Morikawa ${ }^{3}$, Keiichi Ishii ${ }^{4}$ and Keiko Yamagami ${ }^{1}$
}

\begin{abstract}
A 59-year-old man with a history of prostate hyperplasia was admitted to our hospital for further examination of a lung mass and renal dysfunction. Lung biopsy specimens revealed that inflammatory cells had infiltrated into the blood vessel walls. We initially suspected lymphomatoid granulomatosis, but Epstein Barr virus-encoded small RNA was negative. However, 50\% of the infiltrating plasma cells were positive for IgG4. Furthermore, the kidneys and prostate contained abundant IgG4-positive plasma cells. He was diagnosed with IgG4-related sclerosing disease even though serum IgG4 levels were not elevated $(45.7 \mathrm{mg} / \mathrm{dL})$. Prednisolone reduced the lung masses and ameliorated renal function, but the serum IgG4 level increased ( $377 \mathrm{mg} / \mathrm{dL}$ ). Seronegative IgG4-related sclerosing disease should be considered when patients present with such symptoms and treatment responses, and the secretion of IgG4 might be blocked by its active synthesis.
\end{abstract}

Key words: IgG4-related sclerosing disease, lymphomatoid granulomatosis

(Inter Med 49: 2007-2011, 2010)

(DOI: 10.2169/internalmedicine.49.3630)

\section{Introduction}

Kamisawa and Okamoto originally proposed IgG4-related sclerosing disease (IgG4-RSD) while studying autoimmune pancreatitis (AIP) (1). Abundant infiltration of IgG4-positive plasma cells and lymphocytes with fibrosis in various organs are characteristic features of IgG4-RSD. Serum IgG4 levels are significantly increased and useful for diagnosis (2). Lung involvement in IgG4-RSD has increasingly been discovered and it usually manifests as inflammatory pseudotumors $(3,4)$ or interstitial pneumonia $(5,6)$. Grade 1 lymphomatoid granulomatosis (LYG-G1)-like lesions characterized by lymphoplasmacytic vasculitis might also be features of IgG4-related lung disease (7-9).

Here, we describe a patient with LYG-G1-like lung lesions with abundant infiltration of IgG4-positive plasma cells in the lungs, kidneys and prostate despite being seronegative for IgG4-RSD. We also discuss the possible pathological mechanisms of seronegative IgG4-RSD.

\section{Case Report}

A 59-year-old man had been treated with $\alpha$-blocking agents since being diagnosed with prostatic hyperplasia accompanied by urinary frequency and dysuria two years previously. He had ill-defined consolidation in both lungs at a medical check-up for prostatic hyperplasia. Computed tomography (CT) revealed nodular lesions in both lower lobes (Fig. 1A). Fluorodeoxyglucose positron emission tomography (FDG-PET) revealed accumulation in the right lower lobe, mediastinal lymph nodes, kidneys and prostate (Fig. 1B). Clinically, lung cancer was suspected, and bronchoscope was performed. However, histological examination

\footnotetext{
${ }^{1}$ Department of Internal Medicine, Osaka City General Hospital, Osaka, ${ }^{2}$ Department of Pathology, Osaka City General Hospital, Osaka, ${ }^{3}$ Department of Nephrology and Hypertension, Osaka City General Hospital, Osaka and ${ }^{4}$ Department of Urology, Osaka City General Hospital, Osaka

Received for publication March 8, 2010; Accepted for publication May 25, 2010

Correspondence to Dr. Tomoko Miyashita, minet56@yahoo.co.jp
} 

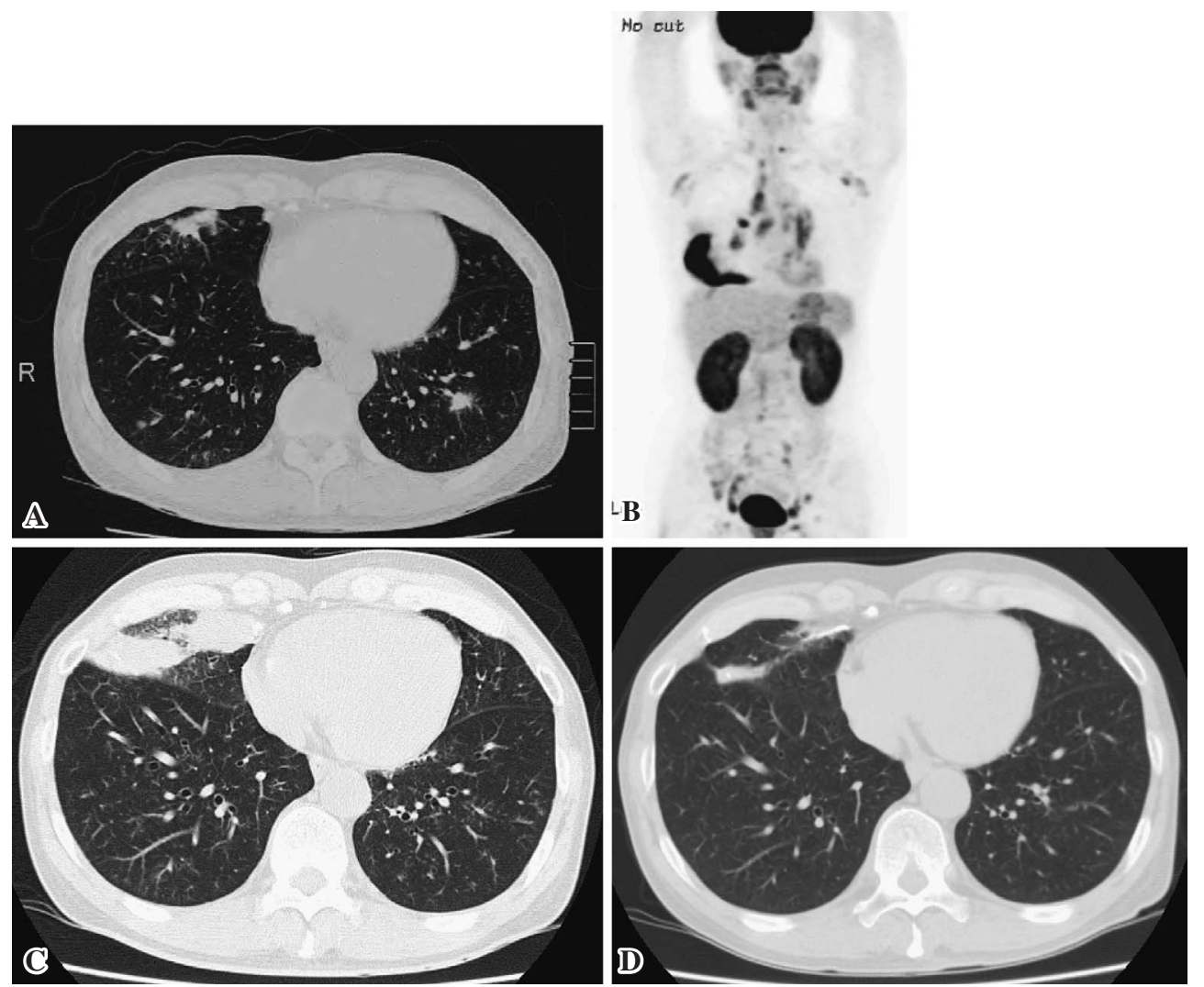

Figure 1. A, C and D: CT scans upon admission, four months after lung biopsy and one month after corticosteroid therapy, respectively. B: Positron emission tomography with $\left[{ }^{18} \mathrm{~F}\right]$ fluorodeoxyglucose on admission revealed significant FDG uptake by the right lower lobe, mediastinal lymph nodes, kidneys and prostate.

was negative for malignancy. He was referred to our hospital for further evaluation. Video-associated thoracoscopic lung biopsy specimens revealed vasculitis-like lesions, namely inflammatory cells that had massively infiltrated the walls of the blood vessels and subendothelium. Inflammatory cells comprised small lymphocytes and plasma cells without atypical cells (Fig. 2A and B). Although the pathology indicated a diagnosis of LYG, in situ hybridization showed that the patient was negative for Epstein Barr virusencoded small RNA (EBER). The lung masses gradually increased after surgery (Fig. 1C) and he was referred to our department for further evaluation and treatment. Specimens were immunostained for IgG and $\mathrm{IgG} 4$ as we suspected $\mathrm{IgG}$ 4-RSD. Most infiltrating plasma cells were positive for IgG and the ratio (\%) of IgG4- to total IgG-positive plasma cells was approximately $50 \%$ (Fig. 2C). Because IgG4-related lung disease is histopathologically indistinguishable from LYG by HE-staining, the patient was admitted to our department for further examination and treatment. His laboratory findings upon admission were as follows: peripheral white cells, 7,780/ $\mu \mathrm{L}$; peripheral eosinophils, 490/ $\mu \mathrm{L}$; C-reactive protein, $1.41 \mathrm{mg} / \mathrm{dL}$. Hepatic and pancreatic functions were normal. Serum $\gamma$-globulin, IgG, IgA and $\operatorname{IgM}$ levels were $3.19 \mathrm{~g} / \mathrm{dL}$ and 4,224, 202 and $76 \mathrm{mg} / \mathrm{dL}$ respectively. Serum levels of $\operatorname{IgG}$ subclasses were: $\operatorname{IgG} 1, \operatorname{IgG} 2, \operatorname{IgG} 3$ and $\mathrm{IgG} 4$, 2,130, 1,750, 192 and $45.7 \mathrm{mg} / \mathrm{dL}$, respectively, showing that the serum IgG4 level was not elevated. Values for antinuclear antibody, myeloperoxidase-anti-neutrophil cytoplasmic antibody (MPO-ANCA), proteinase-3-anti-neutrophil cytoplasmic antibody (PR3-ANCA) and rheumatoid factor were 1:320 (homogeneous pattern), 1.8, 5.1 and $65 \mathrm{IU} / \mathrm{mL}$, respectively. Anti-SS-A/Ro and anti-SS-B/La antibodies were negative.

The serum creatinine level was $1.40 \mathrm{mg} / \mathrm{dL}$ at the time of surgery, but increased to $2.46 \mathrm{mg} / \mathrm{dL}$ on admission. An abdominal CT scan showed swelling of both kidneys and a renal biopsy revealed widespread interstitial fibrosis and tubular atrophy accompanied by massive infiltration of lymphocytes, plasma cells and rare eosinophils. Immunostaining showed that the infiltrating plasma cells were $\operatorname{IgG}$ and $\mathrm{IgG} 4$ positive (Fig. 2D, E and F).

Prostate tissue samples obtained by transrectal biopsy showed lymphocyte and plasma cell infiltration. Many IgG 4-positive cells had infiltrated into the prostate (Fig. 2G, H and I).

We diagnosed IgG4-related lung disease, interstitial nephritis and prostatitis and started the patient on oral prednisolone (PSL; $40 \mathrm{mg} /$ day) for 21 days and then tapered the dose. A CT scan one month later showed that the lung mass had become smaller (Fig. 1C). His renal function improved (creatinine, $1.18 \mathrm{mg} / \mathrm{dL}$ ) and the frequency of urination decreased without $\alpha$-blockers. 


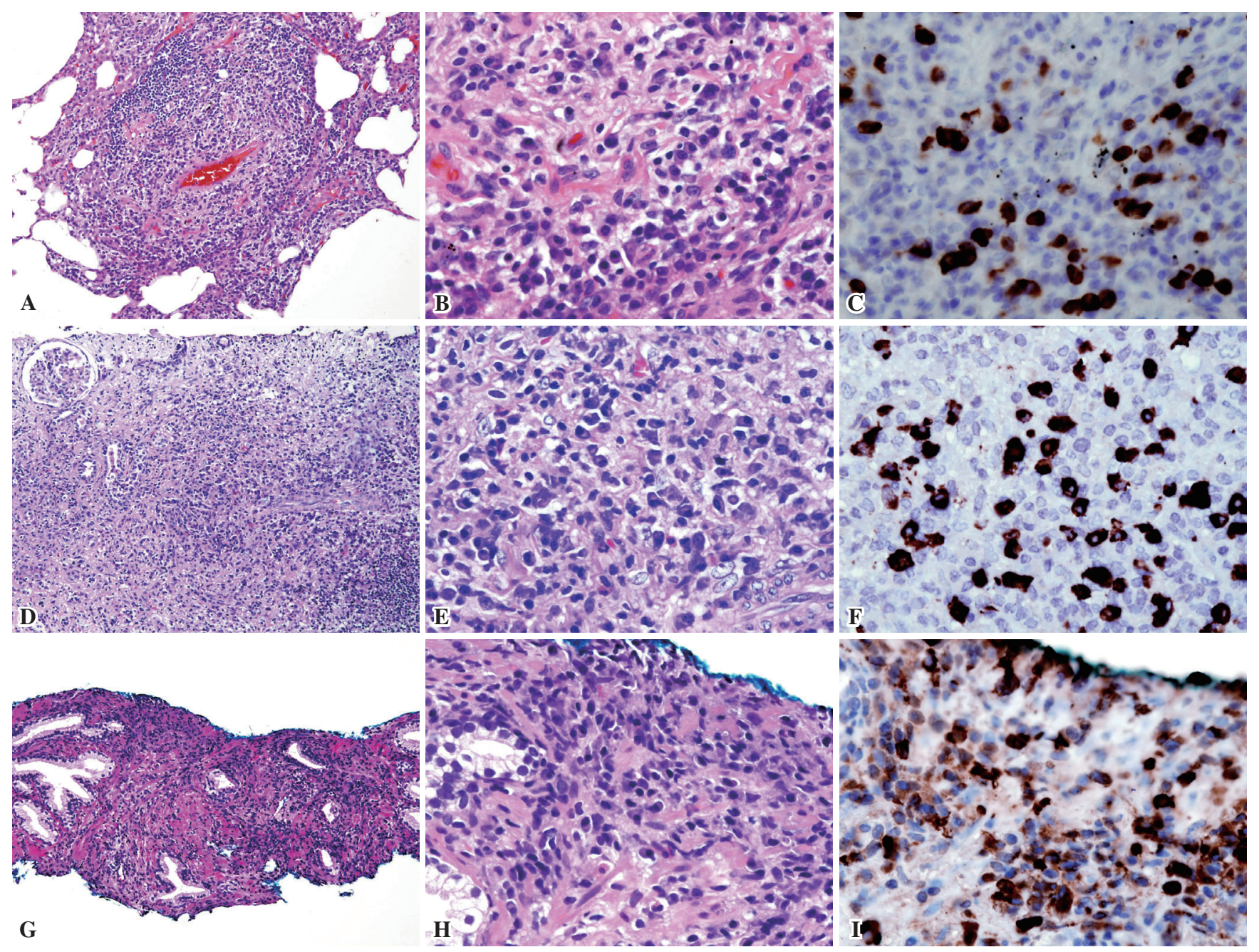

Figure 2. A and B: Hematoxylin and Eosin staining of lung ( $\times 100$ and 400). C: Immunohistochemical staining for IgG4 in lung. D and E: Hematoxylin and Eosin staining of kidney $(\times 100$ and 400). F: Immunohistochemical staining for IgG4 in kidney. G and H: Hematoxylin and Eosin staining of prostate $(\times 100$ and 400$)$. I: Immunohistochemical staining for IgG4 in prostate.

Despite the clinical improvements conferred by PSL, serum IgG4 levels were notably increased 1-month following the start of treatment; serum levels of total $\operatorname{IgG}$ and $\operatorname{IgG}$ subclass were as follows: total $\mathrm{IgG}, \mathrm{IgG} 1, \mathrm{IgG} 2, \mathrm{IgG} 3$ and $\mathrm{IgG} 4,1,697,963,720,27.4$ and $377 \mathrm{mg} / \mathrm{dL}$, respectively. Thereafter, the serum IgG4 level decreased to $105 \mathrm{mg} / \mathrm{dL} 6$ months following the start of treatment (Fig. 3).

\section{Discussion}

Angiocentric and angiodestructive infiltration of lymphocytes and plasma cells characterize rare LYG, which predominantly involves the lungs (10). The exact pathogenesis of LYG is unknown, but it is now considered to be an EBVassociated B cell lymphoma. The disease is graded from I to III based on the number of atypical EBV-positive B cells and the presence of necrosis (11). Few $(<5 / \mathrm{HPF})$ or absent EBV-positive B cells together with absent or minimal necrosis are features of LYG-GI. Although the histological findings of the present patient were similar to those of LYG-G1, the abundance of IgG4-positive plasma cells indicated IgG4- related lung disease.

The prognosis of LYG-G1 is variable (12) as some patients have an excellent response to corticosteroid, whereas others progress to malignant lymphoma. One explanation might be that some of the lesions that were described as LYG-G1 were actually IgG4-related lung disease. Thus, LYG-G1 without EBV-positive B cells might be a heterogeneous disease and LYG-G1 might be classifiable as true LYG-GI (EBV-related) and LYG-G1-like (IgG4-related) types. IgG4-related LYG is rare as IgG4-related lung diseases and we compiled the past cases into Table 1.

The present patient did not have elevated serum IgG4 despite the abundant infiltration of IgG4-positive plasma cells in the lungs, kidneys and prostate. In contrast to initial reports indicating that $95 \%$ of patients with AIP have high serum levels of IgG4 (2), a recent study found that the sensitivity of serum IgG4 to diagnose AIP is actually $76 \%$ (34 of 45 patients), which is quite low. That is, 11 patients in that study were seronegative for AIP (13). Importantly, among the 11 patients with normal serum IgG4 levels, tissues in seven of them were abundantly infiltrated with IgG4-positive 


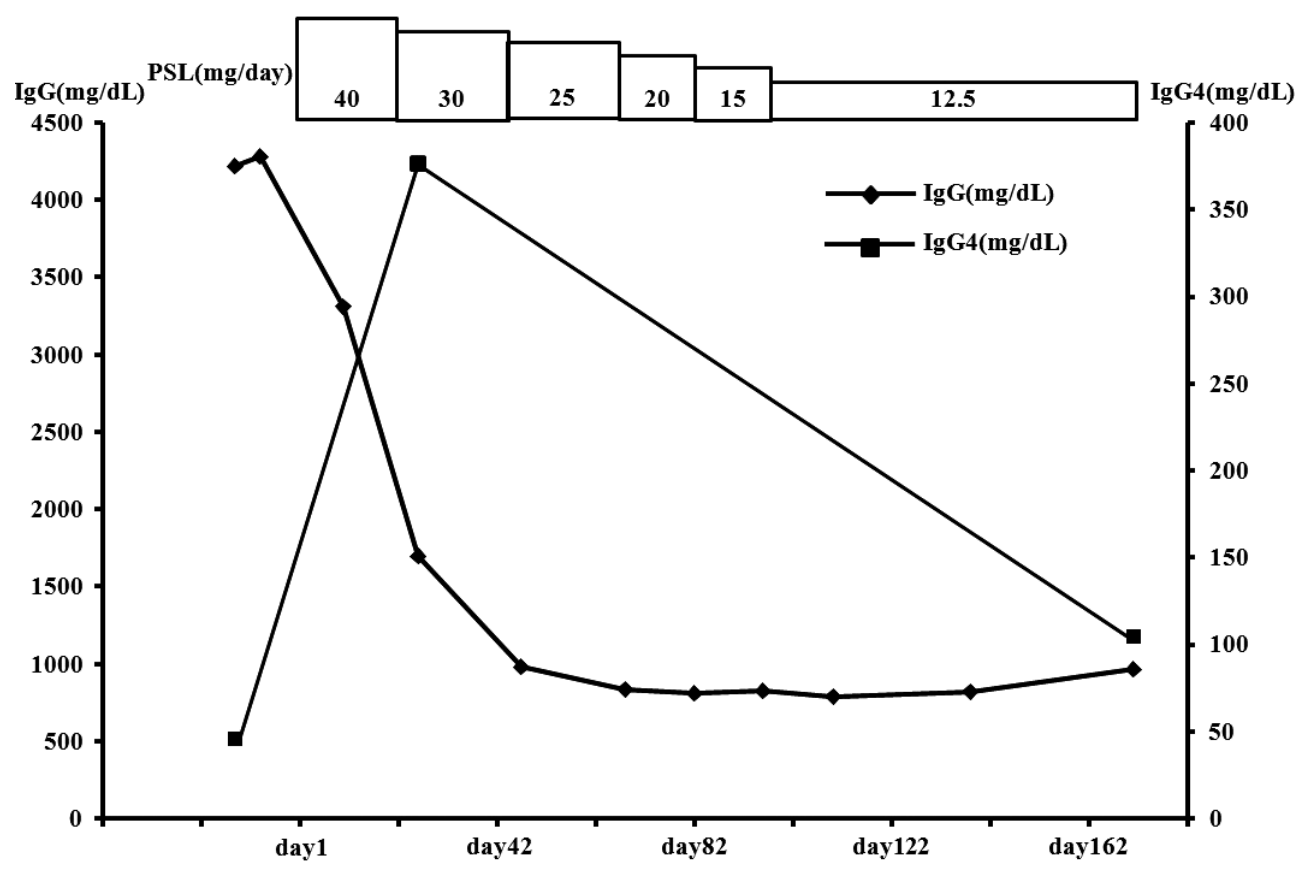

Figure 3. Clinical course after admission.

Table 1. Reported Cases of Lung Involvement of IgG4-related Sclerosing Disease

\begin{tabular}{|c|c|c|c|}
\hline case & Reference & Levels of Serum IgG4 & Extrapulmonary Lesions \\
\hline 1 & 7 & IgG4 was not evaluated & $\begin{array}{l}\text { Nephritis, sialadenitis, and } \\
\text { pancreatic pseudotumor }\end{array}$ \\
\hline 2 & 7 & IgG4 was not evaluated & $\begin{array}{c}\text { sialadenitis, remote history of } \\
\text { nephritis, and lymphadenopathy }\end{array}$ \\
\hline 3 & 8 & $196 \mathrm{mg} / \mathrm{dL}$ & $\begin{array}{l}\text { Sicca syndrome and bilateral } \\
\text { awelling of the parotid glands and } \\
\text { submandibularglands }\end{array}$ \\
\hline 4 & 8 & IgG4 was not evaluated & none \\
\hline 5 & 8 & IgG4 was not evaluated & none \\
\hline 6 & 9 & $499 \mathrm{mg} / \mathrm{dL}$ & $\begin{array}{c}\text { inflammatory lesions of } \\
\text { submandibulargland, bile duct, } \\
\text { and prostate }\end{array}$ \\
\hline 7 & present study & $45.7 \mathrm{mg} / \mathrm{dL}$ & interstitial nephritis and prostatiti \\
\hline
\end{tabular}

plasma cells, a sign that is considered the gold standard for a diagnosis of IgG4-RSD. Thus, seronegative IgG4-RSD clearly exists. However, the mechanism of seronegativity in patients with IgG4-RSD has not been studied to date.

One possible explanation for the seronegativity is that serum IgG4 levels reflect disease extent and/or activity. Various organs of patients with AIP associated with high levels of IgG4 have IgG4-positive plasma cells, whereas they are confined to the pancreas of patients with normal serum IgG 4 levels (13). However, this explanation was unlikely for our patient because IgG4-positive plasma cells had abundantly infiltrated various organs and his serum $\mathrm{IgG} 4$ level increased after corticosteroid therapy.

We considered that the mechanism of seronegativity in the present case is defective in the process of secretion not in the structure of IgG4, because the serum IgG4 levels became high following the start of corticosteroid therapy. Immunoglobulin (Ig) synthesized by ribosomes in plasma cells enters the rough endoplasmic reticulum (RER) and is secreted directly from the RER. The precise mechanism of IgG secretion from plasma cells is unknown. However, most of the Ig synthesized in patients with multiple myeloma is abolished via the Golgi apparatus, that is, plasma cells suppress Ig secretion (self-control) when plasma cells actively 
synthesize Ig (14). Likewise, the secretion of IgG4 may be suppressed by active synthesis of IgG4 in IgG4-RSD. The IgG4 level in the present patient increased after therapy with corticosteroid, which directly suppresses Ig synthesis, indicating that his plasma cells could not secrete IgG4 due to suppression through active Ig synthesis. Thus, the most plausible explanation for the seronegativity of our patient might be as follows. Active synthesis blocked IgG4 secretion, and then corticosteroid suppressed the synthesis which restored IgG4 secretion from the plasma cells. However, in the previous cases with seronegative IgG4-RSD, structural defects in plasma cells have not been proven and serum IgG 4 levels have not been examined following the start of corticosteroid therapy. Serum IgG4 levels should be examined following the start of corticosteroid therapy to establish the precise mechanism of seronegativity in IgG4-RSD.

The negative predictive value of the serum IgG4 level for AIP is very high (99\%) because IgG4-RSD is rare (13). Nevertheless, the recognition of seronegative IgG4-RSD is important because the absence of high serum IgG4 levels could delay a diagnosis of IgG4-RSD and worsen the prognosis.

The kidneys and prostate of the present patient also contained abundant IgG4-positive plasma cells. Tubulointerstitial nephritis (TIN) is most widely recognized as an IgG4related renal disease and biopsy specimens show dense lymphoplasmacytic and eosinophilic infiltration with fibrosis and atrophic renal tubules (15). The histological findings of our patient were compatible with those of IgG4-related TIN. Chronic prostatitis is classified by the National Institutes of Health into 4 major types according to the underlying cause and clinical presentation, whereas IgG4-related prostatitis is rarely reported (16). Category III prostatitis is characterized by lower genitourinary symptoms and a non-infectious etiology including autoimmunity has been proposed. Category III prostatitis might include IgG4-RSD.

In summary, we described LYG-1-like lung lesions with abundant infiltration of IgG4-positive plasma cells in the lungs, kidneys and prostate despite normal serum IgG4 levels. Interestingly, the IgG4 level increased after corticosteroid therapy. This experience indicates that seronegative IgG 4-RSD is a disease entity and that a histological examination is mandatory for diagnostic confirmation.

\section{References}

1. Kamisawa T, Okamoto A. Autoimmune pancreatitis: proposal of IgG4-related sclerosing disease. J Gastroenterol 41: 613-625, 2006.

2. Hamano H, Kawa S, Horiuchi A, et al. High serum IgG4 concentrations in patients with sclerosing pancreatitis. N Engl J Med 344: 732-378, 2001.

3. Zen $\mathrm{Y}$, Kitagawa $\mathrm{S}$, Minato $\mathrm{H}$, et al. IgG4-positive plasma cells in inflammatory pseudotumor (plasma cell granuloma) of the lung. Hum Pathol 36: 710-717, 2005.

4. Tsuboi H, Inokuma S, Setoguchi K, et al. Inflammatory pseudotumors in multiple organs associated with elevated serum IgG4 level: recovery by only a small replacement dose of steroid. Intern Med 47: 1139-1142, 2008.

5. Takato H, Yasui M, Ichikawa $Y$, et al. Nonspecific interstitial pneumonia with abundant IgG4-positive cells infiltration, which was thought as pulmonary involvement of IgG4-related autoimmune disease. Intern Med 47: 291-294, 2008.

6. Taniguchi T, Ko M, Seko S, et al. Interstitial pneumonia associated with autoimmune pancreatitis. Gut 53: 770; author reply-1, 2004.

7. Deshpande V, Chicano S, Finkelberg D, et al. Autoimmune pancreatitis: a systemic immune complex mediated disease. Am J Surg Pathol 30: 1537-1545, 2006.

8. Yamashita K, Haga H, Kobashi Y, Miyagawa-Hayashino A, Yoshizawa A, Manabe T. Lung involvement in IgG4-related lymphoplasmacytic vasculitis and interstitial fibrosis: report of 3 cases and review of the literature. Am J Surg Pathol 32: 1620-1626, 2008.

9. Hamed G, Tsushima K, Yasuo M, et al. Inflammatory lesions of the lung, submandibular gland, bile duct and prostate in a patient with IgG4-associated multifocal systemic fibrosclerosis. Respirology 12: 455-457, 2007.

10. Liebow AA, Carrington CR, Friedman PJ. Lymphomatoid granulomatosis. Hum Pathol 3: 457-558, 1972.

11. Beaty MW, Toro J, Sorbara L, et al. Cutaneous lymphomatoid granulomatosis: correlation of clinical and biologic features. Am J Surg Pathol 25: 1111-1120, 2001.

12. Katzenstein AL, Carrington CB, Liebow AA. Lymphomatoid granulomatosis: a clinicopathologic study of 152 cases. Cancer $\mathbf{4 3}$ : 360-373, 1979.

13. Ghazale A, Chari ST, Smyrk TC, et al. Value of serum IgG4 in the diagnosis of autoimmune pancreatitis and in distinguishing it from pancreatic cancer. Am J Gastroenterol 102: 1646-1653, 2007.

14. Raubenheimer EJ, Dauth J, Senekal JC. Non-secretory IgA kappa myeloma with distended endoplasmic reticulum: a case report. Histopathology 19: 380-382, 1991.

15. Uchiyama-Tanaka $Y$, Mori $Y$, Kimura T, et al. Acute tubulointerstitial nephritis associated with autoimmune-related pancreatitis. Am J Kidney Dis 43: e18-e25, 2004.

16. Yoshimura Y, Takeda S, Ieki Y, Takazakura E, Koizumi H, Takagawa K. IgG4-associated prostatitis complicating autoimmune pancreatitis. Intern Med 45: 897-901, 2006.

(C) 2010 The Japanese Society of Internal Medicine

http://www.naika.or.jp/imindex.html 